\title{
Saving the Moving Position on the Continuous Passive Motion Machine for Rehabilitation of Shoulder Joints
}

\author{
Antonius Hendro Noviyanto \\ Politeknik Mekatronika Sanata Dharma, Yogyakarta, Indonesia \\ Corresponding Author: hendro@pmsd.ac.id
}

(Received 03-06-2019; Revised 29-10-2019; Accepted 29-10-2019)

\begin{abstract}
This paper presents the results of the motion therapy device Continuous Passive Motion (CPM) Machine which is applied to the shoulder joint with storage movement. The process of joint rehabilitation is carried out by continuous passive movements. This movement is intended not to overload the work of the muscles and there is no stiffness in the joints after surgery or stroke patients or patients who have carried out immobilization for quite a long time. The CPM Machine developed can move flexion and horizontal abduction. The position storage in this tool is carried out in a range of movements in flexion and horizontal abduction. With the storage of movement can be done movement/therapy exercises in patients with joint stiffness can be done passively and continuously.
\end{abstract}

Keywords: CPM machine, joint rehabilitation, flexion, horizontal abduction

\section{Introduction}

Post-joint surgery patients or patients who are injured in the joints are required to do joint movement exercises. Joint movement exercises can be performed using therapy equipment Continuous Passive Motion Machine (CPM machine) [1]. Basically the 


\section{International Journal of Applied Sciences and Smart Technologies}

Volume 1, Issue 2, pages 121-128

p-ISSN 2655-8564, e-ISSN 2685-9432

working principle of this tool is to move passively and continuously as needed, so that the joints in patients do not experience stiffness [2].

Joint stiffness can be caused by prolonged immobilization of the shoulder joint due to post joint surgery. In addition, joint stiffness can also be caused by patients who are reluctant to move the joint due to the pain felt by the patient. Based on the results of the interview with Dr. Hermawan Nagar Rasyid, Dr., SpOT., M.T., Ph.D., FICS., therapy for joints of the shoulder can be done with flexion and extension as well as horizontal motion adduction and horizontal abduction.

Joint stiffness can be prevented by providing movement exercises that can restore ROM from the shoulder joint [3]. The movement can be given to patients with passive and repeated joint stiffness. Passive movement is a movement that does not require muscle work. Movement exercises are carried out 3-5 times a day, where each exercise is carried out for 1 hour. Movements that can be given include [4]:

1. Flexion / extension: to reduce tissue adhesions

2. Adduction / abduction: to increase the range of motion of the shoulder

3. Rotational motion: to increase the range of motion of the shoulder

Giving training is done by giving the angle of movement gradually with the recommended speed is 1 rotation in 45 seconds [4]. Long immobilization can lead to joint stiffness. Joint stiffness can be reduced by moving the joints. In patients after joint surgery it is recommended to immediately carry out joint movement exercises, so as to reduce the risk of joint stiffness.

CPM machine is a tool that has a method of rehabilitation of damaged joints [5]. Movement exercises using CPM machines can stimulate healing and regeneration of joint cartilage and prevent joint stiffness. The use of CPM machines has the following benefits [5]:

1. Improve nutrition and metabolic activity on the surface of cartilage.

2. Stimulates mesenchymal cells to differentiate inside the surface of the cartilage.

3. Accelerate healing of cartilage and periarticular tissue, such as tendons and ligaments. 


\section{International Journal of Applied Sciences and Smart Technologies}

Volume 1, Issue 2, pages 121-128

p-ISSN 2655-8564, e-ISSN 2685-9432

The use of CPM machine that is in accordance with the procedure, is expected to restore the scope of motion of the joints for sufferers of joint trauma/patients post joint surgery [6].

Based on the need for therapeutic tools for the shoulder joint, then in this study a storage test of movement on the CPM Machine therapeutic apparatus was made. So that the therapeutic apparatus can be used repeatedly with the same movement mode according to the storage of movements that have been carried out.

\section{Design}

CPM Machine that will be designed is a system based on a microcontroller. The system in this tool consists of a microcontroller, DC motor controller, and rotary encoder. The overall system block diagram is shown in Figure 1.

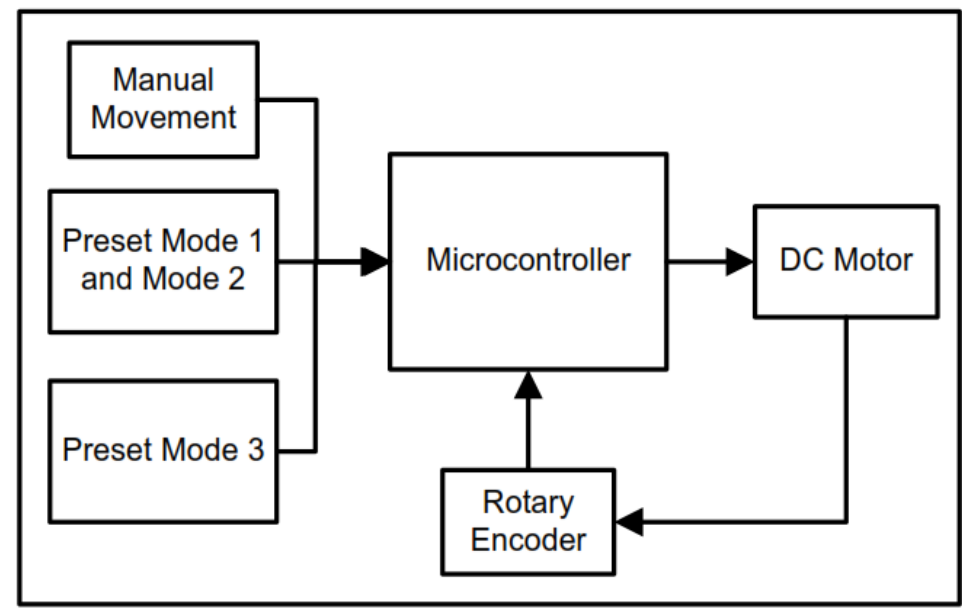

Figure 1. Diagram block system [7]

The therapeutic apparatus that is made can do flexion and horizontal abduction. The flexion movement angle is $20^{\circ}-120^{\circ}$ and the movement angle from horizontal abduction is $0^{\circ}-180^{\circ}$. Besides the movement angle, on this tool people can also set the rotational speed of the tool, namely: 1 RPM, 2 RPM, and 3 RPM. The rotating speed in the tool is controlled using PID control [7].

As in Figure 2, the tool has 3 working modes, namely: 


\section{International Journal of Applied Sciences and Smart Technologies}

Volume 1, Issue 2, pages 121-128

p-ISSN 2655-8564, e-ISSN 2685-9432

1. Mode I : flexion

2. Mode II : horizontal abduction

3. Mode III : save position

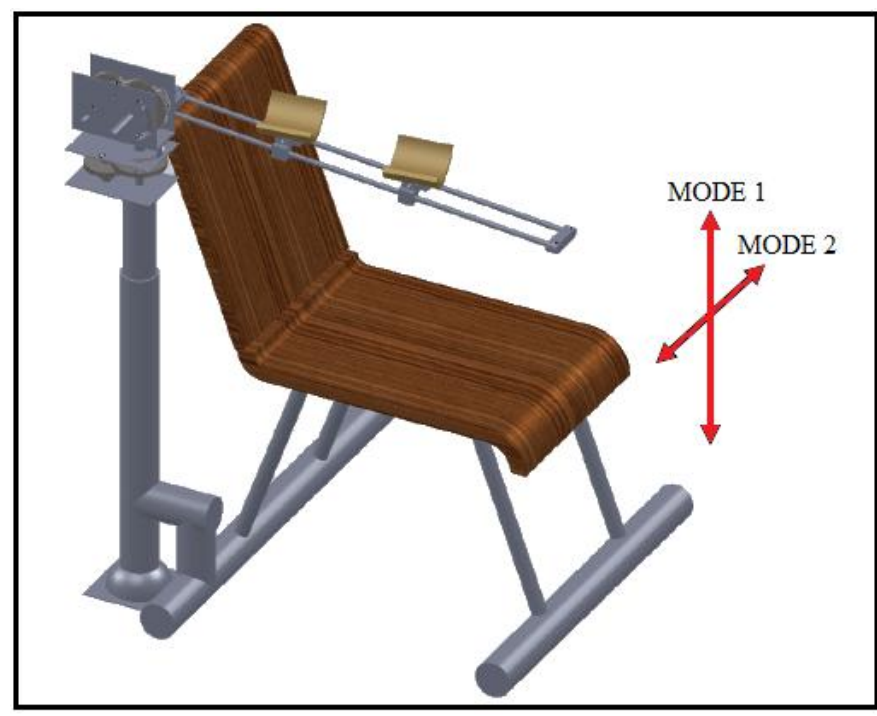

Figure 2. Tool movement mode [7]

In mode I the tool will move flexibly with a movement angle of $20^{\circ}-120^{\circ}$. In mode II the tool will move horizontally abduction with a movement angle of $0^{\circ}-80^{\circ}$ [7]. While in mode III the tool moves according to the position that has been saved. The position stored can change according to the needs with a range of flexed and horizontal abduction movements.

The storage system on the device utilizes the memory facilities available on the microcontroller. Data is stored in the form of data on movement angle and desired type of movement (flexion/abduction).

\section{Method}

The method used in this study is by conducting experiments on tools to get the test results. The results obtained are the results of tool movement angle data and the results of movement based on position storage. 


\section{International Journal of Applied Sciences and Smart Technologies}

Volume 1, Issue 2, pages 121-128

p-ISSN 2655-8564, e-ISSN 2685-9432

In testing the movement angle of the tool, the method that is carried out is by measuring the movement steps of the tool by using a protractor. The results of these measurements will then be compared with the desired requirements.

Testing the movement in accordance with storage is done by comparing the results of the movement stored in memory from the first cycle to the next cycle.

\section{Testing and Discussion}

Testing on this tool is done by testing the movement angle and rotational speed of the rotating tool.

\subsection{Testing and Discussion of Moving Angles}

In flexion movements the measured angles are $30^{\circ}$ and $90^{\circ}$, while the horizontal movement of abduction measured angles are $15^{\circ}$ and $45^{\circ}$. The results of flexion angle test can be seen in Figure 3.a., while the results of horizontal angle of abduction test can be seen in Figure 3.b.

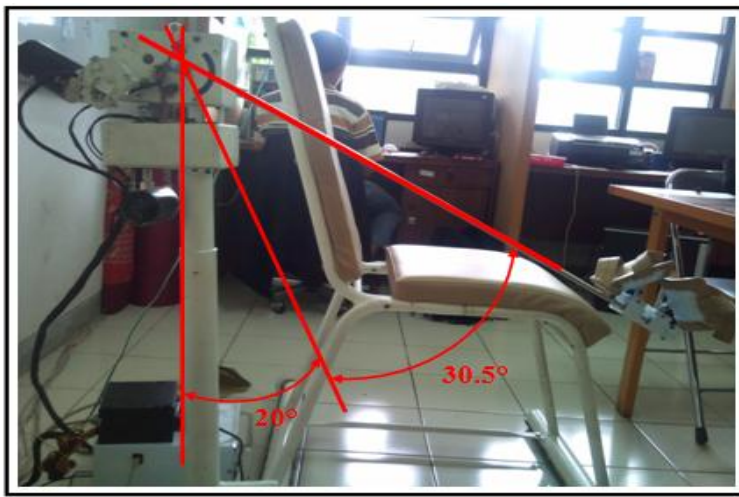

(a)

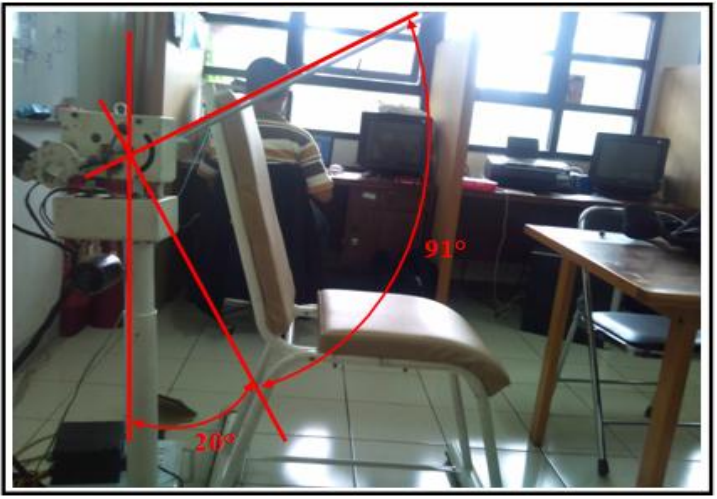

(b)

Figure 3. Testing of flexional motion angle: (a) Motion with angle $30^{\circ}$ (b) Motion with angle $90^{\circ}$ 


\section{International Journal of Applied Sciences and Smart Technologies}

Volume 1, Issue 2, pages 121-128

p-ISSN 2655-8564, e-ISSN 2685-9432

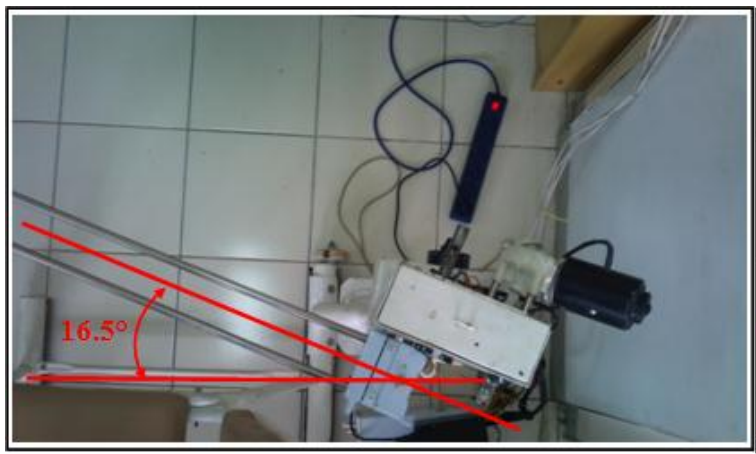

(a)

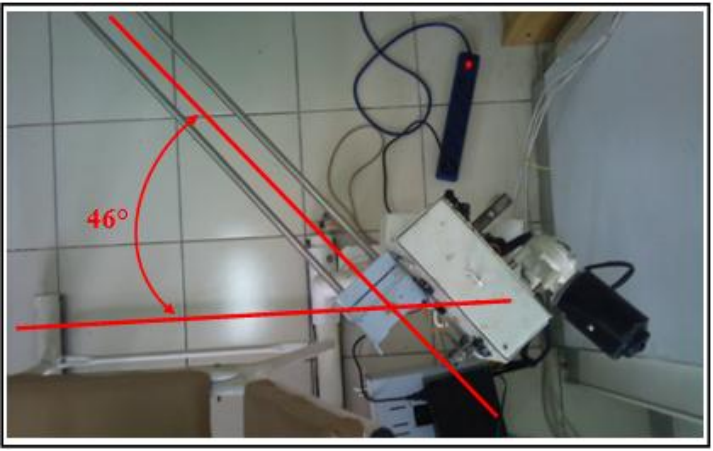

(b)

Figure 4. Testing of horizontal motion angles: (a) Motion with angles $15^{\circ}$ (b) Motion with angles $45^{\circ}$

The graph in Figure 4 shows the results of motor movement that approaches a straight line. The angle of movement and speed of the tool has a result that is not much different from the settings in the tool. The table of comparison of the results of the movement of the tools and settings in the tool can be seen in Table 1.

Table 1. Moving angle test results

\begin{tabular}{cccc}
\hline No. & Tool Movement & Desired Angle & Angle Measurement \\
\hline 1 & Flexion & $30^{\circ}$ & $30.5^{\circ}$ \\
2 & & $90^{\circ}$ & $91^{\circ}$ \\
3 & Horizontal Abduction & $15^{\circ}$ & $16.5^{\circ}$ \\
4 & & $45^{\circ}$ & $46^{\circ}$ \\
\hline
\end{tabular}

\subsection{Movement Testing and Discussion in Accordance with Position Storage}

The arm support that is stored in this position is flexion, abduction, and flexion. Graphs of movement results with position storage can be seen in Figure 5. 


\section{International Journal of Applied Sciences and Smart Technologies}

Volume 1, Issue 2, pages 121-128

p-ISSN 2655-8564, e-ISSN 2685-9432

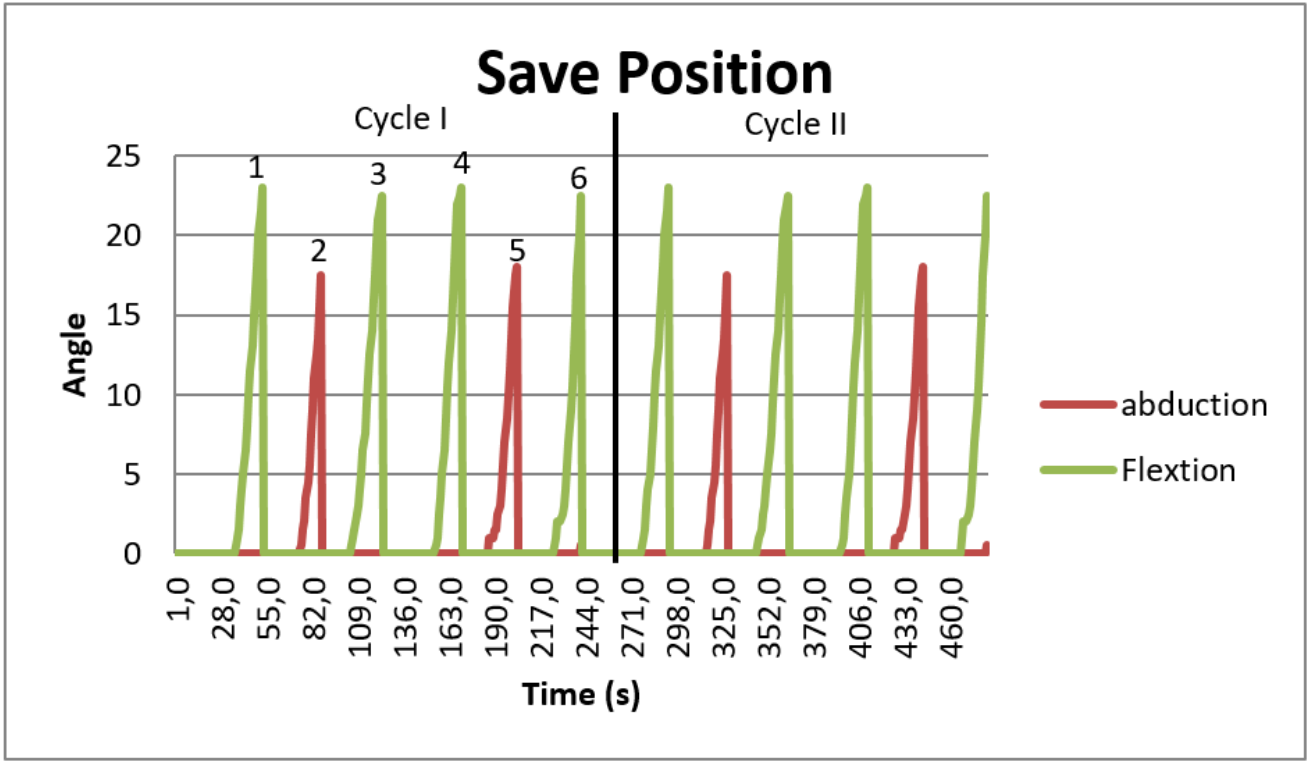

Figure 5. Motion chart with position storage

The position stored in the movement is the movement with the trajectory of flexion and abduction.

Numbers 1, 2, and 3 in the graph show the movement of the arm support. In accordance with the storage of movements that have been carried out, number 1 is a graph of flexion movements. Number 2 in the figure shows a graph of horizontal abduction. While number 3 in the picture shows a graph of flexion movements. The next three movements are movements to return to the starting position. Number 4 is a graph of flexion movements. Number 5 in the figure shows horizontal abduction, where as number 6 from the figure shows flexion. In accordance with the resulting graph, the movement with position storage requires 6 movements for one cycle.

Based on the graph shown, there are similarities in the resulting movement. Movements 1-6 of the first cycle have similarities in movement with movements 1-6 of the second cycle.

\section{Conclusion}

Based on the results of testing that has been done, the tool can work as needed. Data storage can be carried out and can be implemented on the device. Based on the data 


\section{International Journal of Applied Sciences and Smart Technologies}

Volume 1, Issue 2, pages 121-128

p-ISSN 2655-8564, e-ISSN 2685-9432

from the movement of the storage, the tool can store movement in accordance with what is needed and can work according to the movements that have been stored.

\section{Acknowledgements}

The author thank Dr. Hermawan Nagar Rasyid, SpOT., M.T., Ph.D., FICS who provided information about the need for CPM machine therapy devices.

\section{References}

[1] S. Miyaguchi, N. Matsunaga, K. Nojiri, and S. Kawaji, "Impedance control of CPM device with flex-/extension and pro-/supination of upper limbs," IEEE/ASME International Conference on Advanced Intelligent Mechatronics, 2007.

[2] S. Miyaguchi, N. Matsunaga, K. Nojiri, and S. Kawaji, "On effective movement in CPM for shoulder joint," IEEE International Conference on Systems, Man and Cybernetics, 2008.

[3] J. Hamill and K. M. Knutzen, Biomechanical Basis of Human Movement, 3rd Edition, Lippincott Williams \& Wilkins, USA, 2009.

[4] Mujianto, Cara Cepat Mengatasi 10 Besar Kasus Muskuloskeletal dalam Praktik Klinik Fisioterapi, CV. Trans Info Media, 2013.

[5] R. B. Salter, Continuous Passive Motion (CPM): Textbook of Disorders and Injuries of the Musculoskeletal System, Lippincott Williams \& Wilkins, USA, 1999.

[6] S. W. O'Driscoll and N. J Giori, "Continuous Passive Motion (CPM): theory and principles of clinical application," Journal of Rehabilitation Research and Development, 37 (2), 179-188, 2000.

[7] A. H. Noviyanto and M. Richard, "Development of therapy equipment for continuous passive motion machine shoulder joints: track motion control," ISIET Innovation and Technology in Education for 21st Century Supporting Thailand 4.0, 2017. 